\title{
THE SURFACE DIFFUSION OF GOLD ATOMS ON GOLD ELECTRODES IN ACID SOLUTION AND ITS DEPENDENCE ON THE PRESENCE OF FOREIGN ADSORBATES
}

\author{
C. Alonso, R. C. Salvarezza, * J. M. Vara and A. J. Arvia*† \\ Departamento de Química, Facultad de Ciencias, Universidad Autónoma de Madrid, \\ 28049 Madrid, España
}

(Received 25 September 1989; in revised form 16 November 1989)

\begin{abstract}
The surface diffusion coefficient $\left(D_{3}\right)$ of Au atoms in $0.5 \mathrm{M} \mathrm{H}_{2} \mathrm{SO}_{4}$ at $298 \mathrm{~K}$ has been determined from the time dependence of the surface roughness factor of electrodispersed $\mathrm{Au}$ electrodes in $0.5 \mathrm{M} \mathrm{H}_{2} \mathrm{SO}_{4}$. The value of $D_{5}$ for $0.5 \mathrm{M} \mathrm{H}_{2} \mathrm{SO}_{4}$ is $5 \times 10^{-14} \mathrm{~cm}^{2} \mathrm{~s}^{-1}$, a figure which depends considerably on the presence of adsorbable species in solution. Thus, the adsorption of pyridine produces a remarkable decrease of $D_{\mathrm{s}}$, whereas the adsorption of $\mathrm{Cl}^{-}$ion results in the opposite effect. The corresponding values of $D_{\mathrm{s}}$ are $1.2 \times 10^{-14} \mathrm{~cm}^{2} \mathrm{~s}^{-1}$ for $0.5 \mathrm{M} \mathrm{H}_{2} \mathrm{SO}_{4}+0.1 \mathrm{M}$ pyridine, and $2.5 \times 10^{-13} \mathrm{~cm}^{2} \mathrm{~s}^{-1}$ for $0.5 \mathrm{M} \mathrm{H}_{2} \mathrm{SO}_{4}+5 \times 10^{-4} \mathrm{M} \mathrm{KCl}$. These results are interpreted through the influence of the adsorbate on the $\mathrm{Au}$ surface atom diffusion mechanism.
\end{abstract}

Key words: surface diffusion, adsorption, adsorbate, electrodispersed electrodes.

\section{INTRODUCTION}

Surface diffusion of atoms and molecules plays an important role in many physical and chemical heterogeneous processes[1], such as those involved in electrochemical surface reactions. This is the case in the electrocrystallization and electrodissolution of metals[2], and in a large number of electrocatalytic reactions[3]. Therefore, the knowledge of surface diffusion coefficients $\left(D_{\mathrm{s}}\right)$ of atoms (adatoms) and ions (adions) on solid surfaces becomes extremely valuable for understanding those processes at the atomic level, and to estimate rate constants of surface processes involved in the overall reactions. These possibilities encourage further investigations on new methodologies related to the evaluation of $D_{\mathrm{s}}$ for different systems under the widest possible range of ambient conditions.

Recently, a simple method has been presented to estimate the value of $D_{\mathrm{s}}$ for metal atoms in contact with electrolyte solutions[4]. The method is based on the time dependence of the surface roughness factor $(R)$ of electrodispersed metal electrodes immersed in electrolyte solutions, evaluated from combined STM and SEM microscopies and voltammetry data. The value of $R$ can be obtained in different ways. The simplest one for noble metals through the voltammetric charge ratio of well defined electroadsorption/electrodesorption processes for electrodes with different roughnesses, under carefully selected experimental conditions. This is the case

*Permanent address, INIFTA, Sucursal 4, Casilla de Correo 16 (1900) La Plata, Argentina.

†Visiting Professor from the Universidad de La Plata, Argentina. for the $\mathrm{H}$-atom electroadsorption/electrodesorption voltammetric charge ratio for $\mathrm{Pt}$ in acid and the O-atom electroadsorption/electrodesorption voltammetric charge ratio for $\mathrm{Au}, \mathrm{Pt}$ and $\mathrm{Rh}$. $\mathrm{A}$ critical appraisal of the different methods to measure $R$ is given in a forthcoming publication from IUPAC [5].

The complemented STM, SEM and voltammetry results for rough $A u$ and $P t$ electrodes (electrodispersed) in acid solutions allow determination of the value of $R$, and its dependence on the average size of metal particles constituting the rough electrode[4]. The average metal particle size changes according to both the ageing time $(t)$ of the rough metal overlayer and the electrolyte temperature $(T)$. In this way, it was concluded that the structure of this type of electrode[6] approaches either the structure of sticking spheres of uniform diameter[7] or that of a rounded-cap-cylindrical-columnar arrangement $[8]$ with certain average column height $(h)$ and radius $(r)$. For $h \gg r$, the instantaneous value of $R, R(t)$, is given by[8]:

$$
R(t)=\pi h(t) / 3 r(t),
$$

so that for $t=0, r(t=0)=r_{0}$ and $h(t=0)=h_{0}$. For a particle growth controlled by metal atom surface diffusion, the time dependence of $r$ is given by the expression[9]:

$$
\mathrm{d}\left(r^{4}\right) / \mathrm{d} t=2 \gamma a^{4} D_{\mathrm{s}} / \mathrm{k} T
$$

where $a$ is the metal lattice constant, $\gamma$ is the corresponding surface tension and $\mathbf{k}$ is Boltzmann's constant. By integrating equation (2) between $t=0$ and $t=t$, one obtains:

$$
\left(r^{4}-r_{0}^{4}\right)=2 \gamma a^{4} D_{\mathrm{s}} t / \mathrm{k} T .
$$


Furthermore, by considering that $(\mathrm{d} h / \mathrm{d} t) / h \gg$ $(\mathrm{d} r / \mathrm{d} t) / r$, as was timely demonstrated for the rounded-cap-columnar-like structure derived from the STM-SEM data for electrodispersed metal overlayers[8], one can write the following approximation

$$
h(t)=h_{0} \text {. }
$$

From equations (1), (3) and (4) the expression of $R(t)$ is obtained:

$$
R(t)=\pi h_{0} / 3\left[\left(2 \gamma a^{4} D_{s} t / \mathrm{k} T\right)+r_{0}^{4}\right]^{1 / 4} .
$$

The value of $h_{0}$ can be estimated from:

$$
h_{0}=M q / z \mathrm{~F} \rho,
$$

and for an electrodispersed metal layer approaching the rounded - cap-cylindrical - column structural model, the value of $h_{0}$ can be taken as the thickness of the hydrous metal oxide layer (HMOL) from which the electrodispersed metal layer was produced[8]. Thus, in equation (6), $M$ and $\rho$ are the molecular weight and the density of the HMOL, respectively, and $q$ is the HMOL electroreduction charge density. By combining equations (5) and (6) one obtains:

$$
R(t)=\pi M q / 3(z \mathrm{~F} \rho)\left[\left(2 \gamma a^{4} D_{\mathrm{s}} t / \mathbf{k} T\right)+r_{0}^{4}\right]^{1 / 4} .
$$

Hence, the value of $D_{\mathrm{s}}$ for each system can be calculated from equation (7) provided that $\gamma, a$ and $r_{0}$ are known quantities.

The present work refers to the influence of different adsorption processes on the surface diffusion of $\mathrm{Au}$ atoms on electrodispersed $\mathrm{Au}$ electrodes immersed in $0.5 \mathrm{M} \mathrm{H}_{2} \mathrm{SO}_{4}$ as refiected through changes in the $D_{\mathrm{s}}$ value. Very remarkable although opposite dependences of $D_{s}$ after adsorption of either pyridine or $\mathrm{Cl}^{-}$ ions have been observed. The proper ageing process causing the decrease of $R$ is also accompanied by the development of stable $\mathrm{Au}$ crystalline faces with preferred orientations.

\section{EXPERIMENTAL}

The electrochemical set-up consisted of a three compartment Pyrex glass cell provided with a polycrystalline (pc) Au wire electrode (gold $99.99 \%$ purity), a large counter-electrode, and an $\mathrm{Hg} / \mathrm{Hg}_{2} \mathrm{SO}_{4}$ reference electrode. The potential of the working electrode in the text is referred to the normal hydrogen electrode (nhe) scale.

Runs were made in $0.5 \mathrm{M} \mathrm{H}_{2} \mathrm{SO}_{4}$ under purified nitrogen at $298 \mathrm{~K}$. All solutions were prepared from triply distilled water and AR chemicals.

The experimental work comprised the parts outlined below.

\section{The preparation of the electrodispersed $\mathrm{Au}$ electrodes}

The procedure consisted of two subsequent stages. Firstly the HMOL was accumulated on a pc $\mathrm{Au}$ electrode immersed in the electrolyte by applying a repetitive square wave perturbing potential (RSWPP) at $4 \mathrm{kHz}$ between 0.6 and $3.1 \mathrm{~V}$ [10]. In the following stage, the HMOL was voltammetrically electroreduced at $0.02 \mathrm{~V} \mathrm{~s}^{-1}$. At this potential sweep rate the $\mathrm{Au}$ overlayer growth rate is close to $10^{-5} \mathrm{~cm} \mathrm{~s}^{-1}$, resulting in the maximum development of roughness[11].

The electrochemical evaluation of the Au overlayer roughness

The $R$ value of the rough Au working electrode was defined as the voltammetric charge ratio between the O-adatom electrodesorption charge determined for the rough $\mathrm{Au}$ electrode and that of the starting $\mathrm{pc} \mathrm{Au}$ electrode, both determined under comparable preset conditions $[10,12]$.

The roughness decay (ageing) of the electroreduced $\mathrm{Au}$ overlayer

Each electrodispersed Au electrode (specimen) was aged at $298 \mathrm{~K}$ by keeping the electrode immersed in either uncontaminated $0.5 \mathrm{M} \mathrm{H}_{2} \mathrm{SO}_{4}$ or $0.5 \mathrm{M} \mathrm{H}_{2} \mathrm{SO}_{4}$ containing foreign species such as pyridine (Py) or $\mathrm{KCl}$, under open circuit conditions. Periodically, each specimen was carefully rinsed with triply distilled water and transferred to another glass cell containing only $0.5 \mathrm{M} \mathrm{H}_{2} \mathrm{SO}_{4}$ at $298 \mathrm{~K}$, to determine the corresponding $R$ value through voltammetry. This technique also made it possible to check that the foreign adsorbable species was completely removed through rinsing, at least within the sensitivity of voltammetry for this type of surface reaction. Subsequently, the specimen was taken out from $0.5 \mathrm{M} \mathrm{H}_{2} \mathrm{SO}_{4}$ and replaced again into the working solution to continue the ageing process. The overall process for determining the value of $R$ involved about $100 \mathrm{~s}$, a time which was much smaller than the ageing duration itself. On the other hand, no difference was found between the experimental results obtained by ageing the specimen directly into the original cell containing $0.5 \mathrm{M} \mathrm{H}_{2} \mathrm{SO}_{4}$ uvoiding transfer operations, and those obtained by operating discontinuously. Accordingly, the correction in the time scale of the kinetics of the roughness decay appeared to be unnecessary within the range of errors involved in this type of measurement.

\section{RESULTS}

The open circuit potential $\left(E_{\mathrm{oc}}\right)$ of the electrodispersed $\mathrm{Au}$ electrodes in $0.5 \mathrm{M} \mathrm{H}_{2} \mathrm{SO}_{4}$ during the roughness decay (ageing), $30 \mathrm{~s}<t<8 \times 10^{4} \mathrm{~s}$, was in the $0.65-0.55 \mathrm{~V}$ range. It is known that this potential range coincides with that corresponding to the adsorption of sulphate anions on Au[13]. The rate of the electrode roughness decay, as seen from the $R v s$ $t$ plots (Fig. 1a) reproduces the behaviour recently reported for the ageing of $\mathrm{Au}$ electrodispersed electrodes in acid[8].

On the other hand, for the specimen in $0.5 \mathrm{M} \mathrm{H}_{2} \mathrm{SO}_{4}+0.1 \mathrm{MPy}$, the value of $E_{\mathrm{oc}}$ along ageing remains practically within the same range of potentials already mentioned for the plain acid. In both cases the values of $E_{\mathrm{oc}}$ become more positive than the potential of zero charge $\left(E_{\mathrm{z}}\right)$ of $\mathrm{Au}(\mathrm{pc})$, $\mathrm{Au}(100), \mathrm{Au}(110)[14,15]$, although very close to that of $\mathrm{Au}(111)$ [15] in acid and neutral solutions. This fact can be taken as an indication that under the present conditions, both Py adsorption and roughness decay occur at an Au surface which is positively charged 

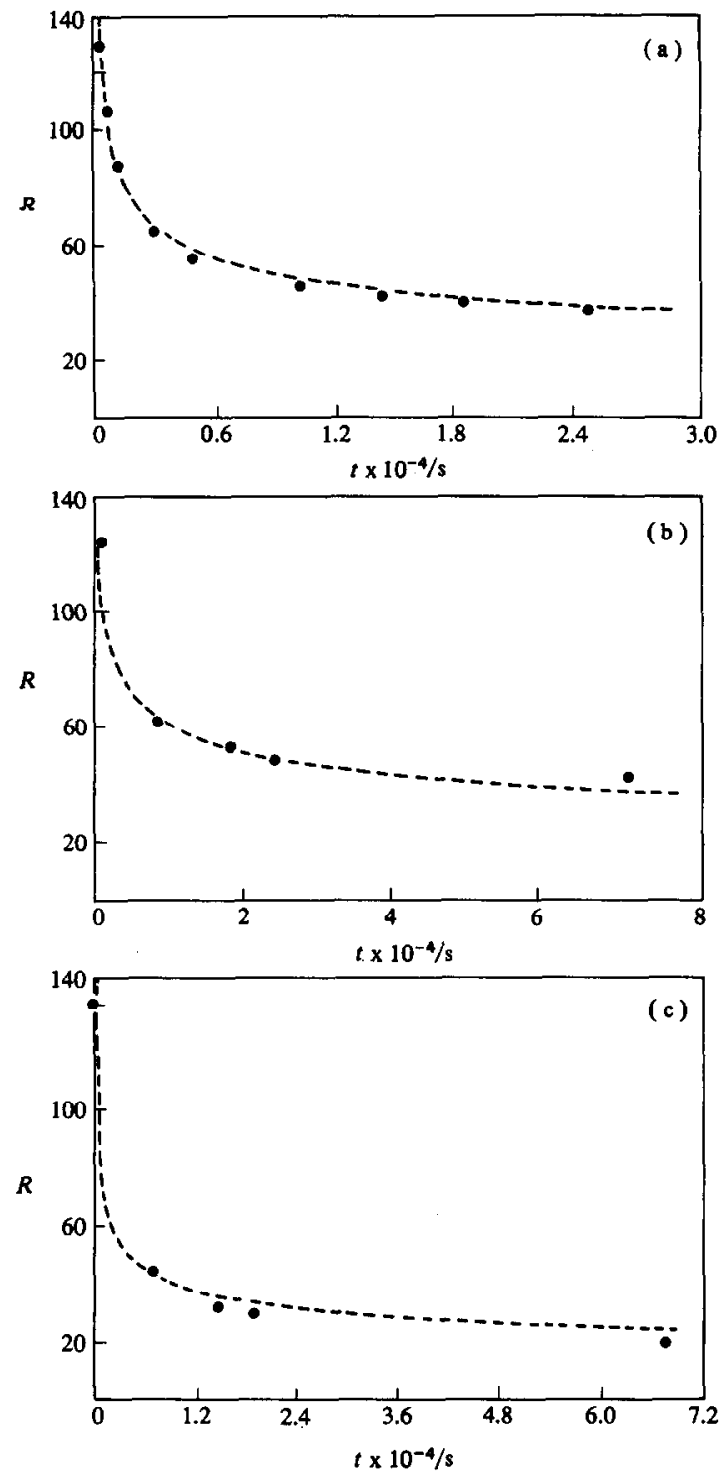

Fig. 1. $R$ vs $t$ plots: (a) $0.5 \mathrm{M} \mathrm{H}_{2} \mathrm{SO}_{4}$; (b) $0.5 \mathrm{M} \mathrm{H}_{2} \mathrm{SO}_{4}+$ $0.1 \mathrm{M} \mathrm{Py}$; (c) $0.5 \mathrm{M} \mathrm{H}_{2} \mathrm{SO}_{4}+5 \times 10^{-4} \mathrm{M} \mathrm{KCl}$. (O) Experimental data; (-.) data calculated with equation (9) and parameters assembled in Table 1.

with respect to $E_{\mathrm{z}}$. Nevertheless, in Py-containing solution, the roughness decay, as deduced from the $R$ vs $t$ plots (Fig. 1b), turns out to be slower than in plain $0.5 \mathrm{M} \mathrm{H}_{2} \mathrm{SO}_{4}$.

The addition of small amounts of $\mathrm{KCl}$ $\left(10^{-5} \mathrm{M}<c<5 \times 10^{-4} \mathrm{M}\right)$ to $0.5 \mathrm{M} \mathrm{H}_{2} \mathrm{SO}_{4}$ results in a much faster roughness decay (Fig. 1c) which in turn depends on $c$, as seen further on through the corresponding values of $D_{\mathrm{s}}$. The $E_{\mathrm{oc}}$ value for this system lies in the $0.45-0.50 \mathrm{~V}$ range, $i e$ it corresponds to a potential range where the adsorption of $\mathrm{Cl}^{-}$ions on Au takes place[13].

The decrease of $R$ for the different solutions, as followed through the change in the O-electrodesorption voltammetric charge, is also accompanied by a change of the voltammetric profile related to the electroadsorption of O-atoms on Au (Fig. 2). As $R$ is changing, the relative contribution of the correspond- ing current peaks is gradually modified to approach, finally, the distribution of the O-electroadsorption current peaks observed for $A u(111)$ in acid solutions[16]. The extent of this change, as estimated from the voltammetric data, seems to operate in the order $0.5 \mathrm{M} \quad \mathrm{H}_{2} \mathrm{SO}_{4}+x \mathrm{M} \mathrm{KCl}>0.5 \mathrm{M} \mathrm{H}_{2} \mathrm{SO}_{4}>$ $0.5 \mathrm{M} \mathrm{H}_{2} \mathrm{SO}_{4}+0.1 \mathrm{M} \mathrm{Py}$ (Fig. 3).

\section{DISCUSSION}

The evaluation of $\mathrm{D}_{s}$ under different ambient conditions

The evaluation of $D_{\mathrm{s}}$ was made through the application of equation (7) which for this purpose was convenicntly rewritten in the form:

$$
R(t)=\pi M q / 3 z \mathrm{~F} \rho\left(P_{1} t+P_{2}\right)^{1 / 4},
$$

where:

$$
P_{1}=2 \gamma a^{4} D_{\mathrm{s}} / \mathrm{k} T
$$

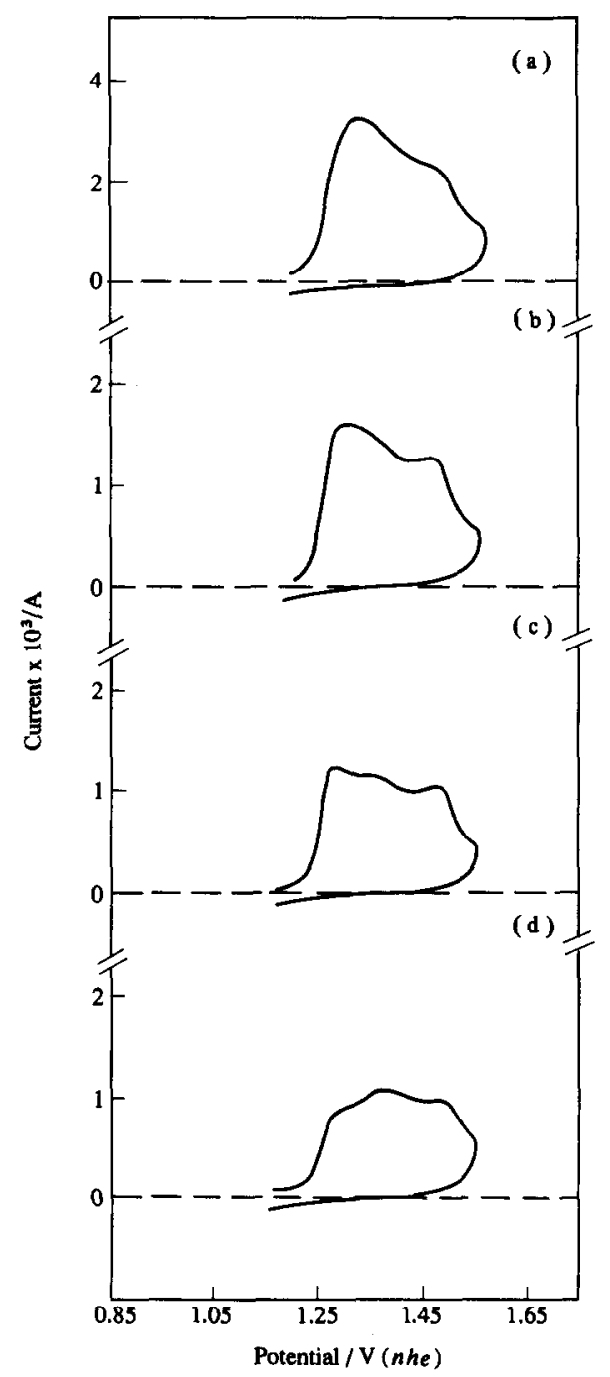

Fig. 2. Voltammograms corresponding to the O-atom electroadsorption on electrodispersed $\mathrm{Au}$ electrodes in $0.5 \mathrm{M} \mathrm{H}_{2} \mathrm{SO}_{4}+0.1 \mathrm{M}$ Py recorded after different roughness decays: (a) 7560; (b) 17800 ; (c) 23500 ; (d) 80000 s. Potential sweep rate: $0.1 \mathrm{~V} \mathrm{~s}^{-1}$. 


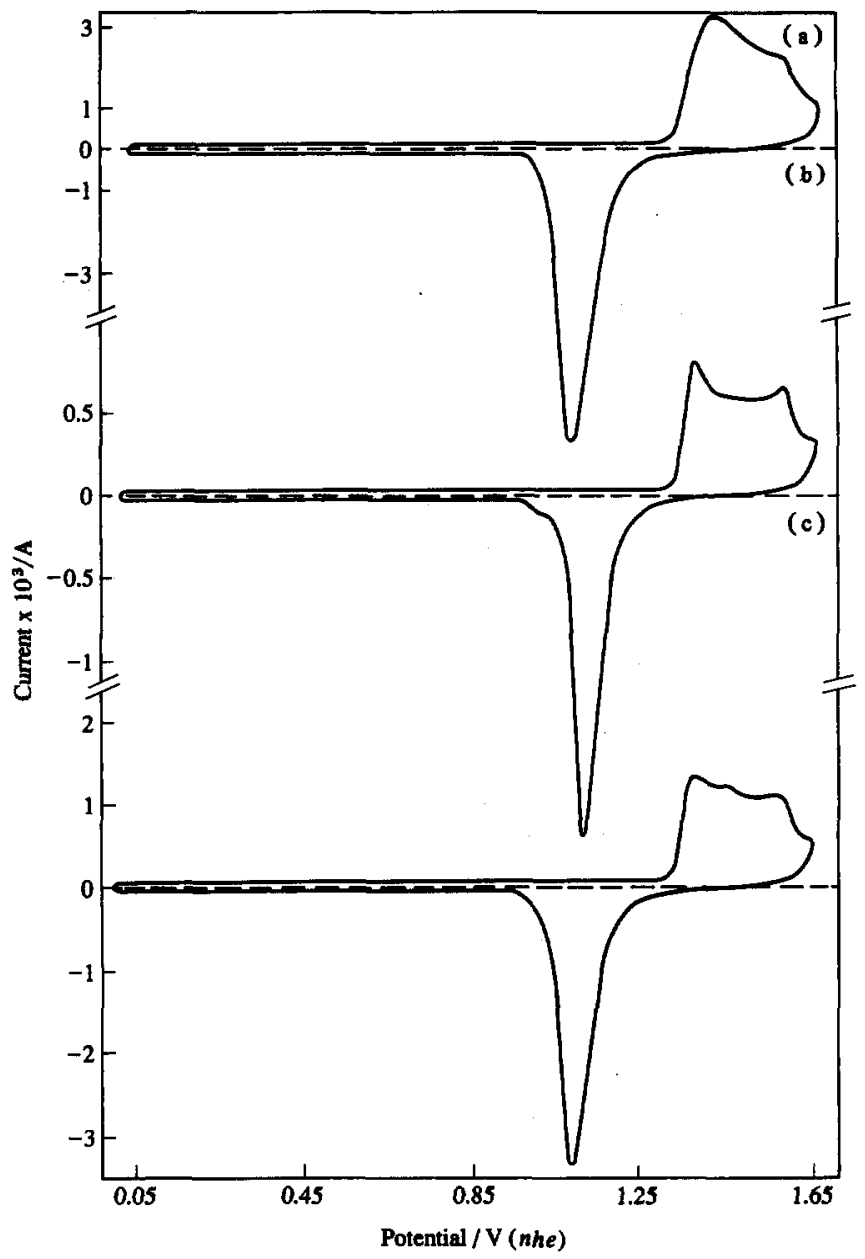

Fig. 3. Voltammograms recorded for Au electrodispersed electrodes obtained after different roughness decays: (a) $t=100 \mathrm{~s}$ for all electrolytes; (b) $t=17800 \mathrm{~s}, 0.5 \mathrm{M} \mathrm{H}_{2} \mathrm{SO}_{4}+1 \times 10^{-5} \mathrm{M} \mathrm{KCl}$; (c) $t=17800 \mathrm{~s}$, $0.5 \mathrm{M} \mathrm{H}_{2} \mathrm{SO}_{4}+0.1 \mathrm{M}$ Py. Potential sweep rate: $0.1 \mathrm{~V} \mathrm{~s}^{-1}$.

and:

$$
P_{2}=r_{0}^{4} \text {. }
$$

The experimental $R$ vs $t$ plots can be reproduced (Fig. 1) within a $10 \%$ error by using equation ( 8 ) with the set of parameters assembled in Table 1 , and further considering $M=442 \mathrm{~g} \mathrm{~mol}^{-1}[17], z=6$, $\rho=11 \mathrm{~g} \mathrm{~cm}^{-3}[18]$, and $q$ values derived from voltammetry. The values of $D_{\mathrm{s}}$ are calculated by using equation (9), the values of $P_{1}, \gamma=900 \mathrm{erg} \mathrm{cm}^{-2}$ and $a=4.07 \times 10^{-8} \mathrm{~cm}[17]$ (Table 1 ). One should note that for the condition $2 \gamma a^{4} D_{\mathrm{s}} t / \mathrm{k} T \gg r_{0}$ equations (7) and (8) can be approximated to:

$$
R(t)=\pi M q / 3 z \mathrm{~F} \rho\left(2 \gamma a^{4} D_{\mathrm{s}} t / \mathrm{k} T\right)^{1 / 4} .
$$

Accordingly, by plotting $1 / R$ vs $t^{1 / 4}$ linear relationships can be obtained. The value of $D_{\mathrm{s}}$ can also be estimated from the slope of those lines. For other systems, this is the usual way of data presentation provided that the mechanism of particle growth is determined by the rate of surface diffusion of adatoms[19].

As previously reported[4], the values of $D_{\mathrm{s}}$ and activation energies for surface diffusion of $\mathrm{Au}$ atoms on $\mathrm{Au}$ in $0.5 \mathrm{M} \mathrm{H}_{2} \mathrm{SO}_{4}$ are greater than those reported in air or vacuum $[19,20]$. The corresponding differences should be attributed to an enhancement of the $\mathrm{Au}$ atom surface diffusion caused to either ion or $\mathrm{H}_{2} \mathrm{O}$ adsorption at the metal surface[19]. Nevertheless, the influence of the ambient conditions on the value of $D_{\mathrm{s}}$ for $\mathrm{Au}$ atoms in $0.5 \mathrm{M} \mathrm{H}_{2} \mathrm{SO}_{4}$, particularly the presence of molecules or ions at the interface, is strikingly demonstrated by the opposite effects produced by $\mathrm{Py}$ and $\mathrm{Cl}^{-}$.

Table 1. Parameters used in equations (8)-(10) and values of $D_{\mathrm{s}}$ at $298 \mathrm{~K}$

\begin{tabular}{lcccc}
\hline \multicolumn{1}{c}{ Electrolyte } & $h_{0} 10^{4} / \mathrm{cm}$ & $P_{1} 10^{27} / \mathrm{cm} \mathrm{s}^{-1}$ & $P_{2}^{1 / 4} 10^{6} / \mathrm{cm}$ & $D_{\mathrm{s}} 10^{14} / \mathrm{cm}^{2} \mathrm{~s}^{-1}$ \\
\hline $0.5 \mathrm{M} \mathrm{H}_{2} \mathrm{SO}_{4}$ & 1.37 & 6.03 & 1.00 & 5.02 \\
$0.5 \mathrm{M} \mathrm{H}_{2} \mathrm{SO}_{4}+0.1 \mathrm{M} \mathrm{Py}$ & 1.22 & 1.5 & 0.92 & 1.24 \\
$0.5 \mathrm{M} \mathrm{H}_{2} \mathrm{SO}_{4}+10^{-5} \mathrm{M} \mathrm{KCl}$ & 1.20 & 19.0 & 1.00 & 15.8 \\
$0.5 \mathrm{M} \mathrm{H}_{2} \mathrm{SO}_{4}+5 \times 10^{-4} \mathrm{M} \mathrm{KCl}$ & 1.52 & 30.0 & 0.85 & 25.0 \\
\hline
\end{tabular}


The influence of the value of $\gamma$ on the evaluation of $\mathrm{D}_{s}$

The values of $D_{\mathrm{s}}$ were calculated by using as a reasonable value for pc Au $\gamma=900 \mathrm{erg} \mathrm{cm}^{-2}[17]$, and it was further assumed that $\gamma$ remains unchanged by the presence of the foreign species added to the acid. However, this may not be the exact case as it is known that the presence of either Py or $\mathrm{Cl}^{-}$ions adsorbates decreases the value of $\gamma$ for metals in contact with aqueous solutions $[14,21]$. Thus, $\Delta \gamma$, the maximum decrease of $\gamma$, is given by:

$$
\Delta \gamma=\gamma(\theta)-\gamma_{0},
$$

where $\gamma_{0}$ and $\gamma(\theta)$ are the surface tension for the uncovered and the adsorbate covered metal surface, respectively, the corresponding degree of coverage by the adsorbate being $\theta$. The value of $\Delta y$ for the $\mathrm{Au} / 0.01 \mathrm{M}$ Py interface is close to $100 \mathrm{erg} \mathrm{cm}^{-2}[14]$. Accordingly, the value of $D_{\mathrm{s}}$ for $\gamma=800 \mathrm{erg} \mathrm{cm}^{-2}$ is $1.3 \times 10^{-14} \mathrm{~cm}^{2} \mathrm{~s}^{-1}$, a figure which is only slightly changed with respect to that previously estimated (Table 1). Therefore, for the surface diffusion of $\mathrm{Au}$ atoms at the $\mathrm{Au} / 0.5 \mathrm{M} \mathrm{H}_{2} \mathrm{SO}_{4}$ interface, any influence of addition of small amounts of $\mathrm{KCl}$ can be neglected[21]. Consequently, it is reasonable to assign the changes in the value of $P_{1}$ principally to changes in $D_{\mathrm{s}}$ as a consequence of the proper surface diffusion mechanism rather than to changes in $\gamma$.

\section{Determination of $r_{0}$}

The values of $r_{0}$ resulting from equation (10) are about $1 \times 10^{-6} \mathrm{~cm}$ for all runs. This figure is very close to that estimated from STM micrographs of freshly prepared electrodispersed Au layers[8]. In this case, $r_{0}$ corresponds to the average radius of the rounded top columns revealed by STM.

The possible mechanism of $\mathrm{Au}$ atom surface diffusion and the interference of the different adsorbates

From the results assembled in Table 1, one can deduce that $\mathrm{Au}-\mathrm{Cl}$ interactions accelerate the collapse of the $\mathrm{Au}$ electrodispersed structure, whereas $\mathrm{Au}-\mathrm{Py}$ interactions tend to protect the rough structure of the Au overlayers. These opposite effects can be explained through specific interferences on Au atom surface diffusion caused by the different adsorbates. For this purpose, it is convenient to consider $E_{o c}$ to provide information about the local energetic conditions and the possible structures prevailing at the metal-solution interface.

The roughness decay of the $\mathrm{Au}$ in $0.5 \mathrm{M} \mathrm{H}_{2} \mathrm{SO}_{4}$ involves an $E_{0 c}$ value lying in the potential range where sulphate ion adsorption takes place, probably as $\mathrm{HSO}_{4}^{-}$ion[13]. Therefore, the surface mobility of $\mathrm{Au}$ atoms should involve complex dynamic cooperative $\mathrm{Au}-\mathrm{HSO}_{4}^{-}-\mathrm{H}_{2} \mathrm{O}$ interactions which must reflect through the $D_{\mathrm{s}}$ value.

To discuss the influence of $\mathrm{Py}$ on the surface mobility of $\mathrm{Au}$ atoms at the $\mathrm{Au} / 0.5 \mathrm{M} \mathrm{H}_{2} \mathrm{SO}_{4}$ interface one should be reminded that for this system at low $\mathrm{pH}, \mathrm{Py}$ exists in solution as $\mathrm{PyH}^{+}[22]$. Otherwise, the value of $E_{\mathrm{oc}}$ in the Py-containing acid is nearly the same as in plain $0.5 \mathrm{M} \mathrm{H}_{2} \mathrm{SO}_{4}$. This indicates that in both solutions the Au surface is positively charged with respect to $E_{\mathrm{z}}$ and that the value of $E_{o c}$ becomes principally determined by either $\mathrm{HSO}_{4}^{-}$or $\mathrm{SO}_{4}^{2-}$ ion adsorption. Therefore, it is possible that $\mathrm{PyH}^{+}$is held at the Au surface through the formation of an ion pair such as $\left(\mathrm{PyH}^{+}-\mathrm{HSO}_{4}^{-}\right)$. This type of structure has already been advanced for explaining the SERS of Py in $\mathrm{Cl}^{-}$ion-containing acid solutions on $\mathbf{A g}$ electrodes[19]. For such a complex adsorbate structure, the surface mobility of Au atoms should be determined by the entire consortial $\mathrm{Au}-\mathrm{HSO}_{4}^{-}-\mathrm{PyH}^{+}-\mathrm{H}_{2} \mathrm{O}$ interaction. Hence, the influence of Py on the surface mobility of Au atoms in aqueous solutions appears to be similar to that induced by Py adsorption on rough metals from the vapour[23]. There is direct evidence of the role played by Py adsorption on pore retention after post-annealing of cold Ag film growth from vapour[23], although in this case the pore structure of the metal is only partially preserved after $15-20 \mathrm{~h}$ annealing at room temperature in UHV due to the high diffusion rate of $\mathrm{Ag}$ atoms. From data given in Fig. 1, the average size of Au particles in the $0.5 \mathrm{M} \mathrm{H}_{2} \mathrm{SO}_{4}+0.1 \mathrm{M} \mathrm{Py}$ after a certain roughness decay becomes smaller than in $0.5 \mathrm{M} \mathrm{H}_{2} \mathrm{SO}_{4}$, although the increase in the average particle size with $t$ cannot be totally hindered by Py adsorption. Accordingly, the value of $D_{\mathrm{s}}$ decreases by a factor of five as compared to $0.5 \mathrm{M} \mathrm{H}_{2} \mathrm{SO}_{4}$.

In $0.5 \mathrm{M} \mathrm{H}_{2} \mathrm{SO}_{4}+\mathrm{KCl}$ solutions, the value of $E_{\mathrm{oc}}$ becomes more negative than that observed for the plain acid, reflecting the adsorption of the $\mathrm{Cl}^{-}$ion at the interface. A progressive replacement of $\mathrm{HSO}_{4}^{-}$by $\mathrm{Cl}^{-}$ions at the Au surface (competitive adsorption) should be expected as the $\mathrm{Cl}^{-}$ion concentration is raised. It is well known that the adsorption of $\mathrm{Cl}^{-}$ion on metals results in both a weaker metal-metal bond[24] and a gradual discharge of the anion. Thus, in the case of $\mathrm{Au}$ at the highest surface coverage by $\mathrm{Cl}^{-}$ions the fomation of $\mathrm{Au}-\mathrm{Cl}$ surface compounds should be assisted. The new structure should enhance the surface mobility of Au atoms as revealed by the high $D_{\mathrm{s}}$ values obtained in these solutions (Table 1). This explanation is consistent with in situ STM data for $\mathrm{Au}$ in $\mathrm{Cl}^{-}$ion-containing $0.5 \mathrm{M} \mathrm{H}_{2} \mathrm{SO}_{4}[25,26]$. In this case, the formation of a surface compound[25] and the absence of roughening[26] due to the increase in the step motion induced by $\mathrm{Cl}^{-}$ion adsorption have been observed.

Possible surface reconstruction coupled to the roughness decay of electrodispersed $\mathrm{Au}$

From the inspection of the voltammograms obtained during ageing, the corresponding changes in the O-electroadsorption peak multiplicity can be related to the development of certain preferred crystalline orientations. This effect becomes practically independent of the electrolyte composition. The comparison of these results to those reported for $\mathrm{Au}$ single crystals under comparable conditions[16] suggest that the ageing of electrodispersed $\mathrm{Au}$ results in a predominance of $\mathrm{Au}(111)$ crystallites. This fact is not surprising if one takes into account that heating of $\mathrm{Au}$ deposits results also in $\mathrm{Au}(111)$ crystallites as revealed by X-ray diffractometry[27]. Furthermore, the correlation between the $D_{\mathrm{s}}$ values and the rate of reconstruction indicates that the latter is controlled by the surface diffusion of $\mathrm{Au}$ atoms. Consequently, 
the reconstruction of the $\mathrm{Au}$ electrode surface in aqueous electrolytes yielding a more compact lattice array becomes dependent on the time window of the experiment, the temperature[4] and the electrolyte composition, whether it contains species which either accelerate or hinder the reconstruction process.

\section{Some consequences of surface diffusion results}

The precedent results have implications in different areas of electrochemistry. One of them concerns the conditions for using electrodispersed metal electrodes and, in general, surface area electrodes in fields such as electrocatalysis. According to the present data a careful selection of the electrolyte composition, temperature and time range for the experiments is necessary to assure that the electrode reaction is not influenced by changes at the solid metal electrode surface. In this respect $\mathrm{Au}$ appears to behave as a rather soft material for electrochemical reactions at room temperature.

The influence of $\mathrm{Cl}^{-}$ions on the $D_{\mathrm{s}}$ values even at low concentrations becomes attractive to sustain recent stress metal corrosion cracking theories[2]. In this respect, the increase in $D_{\mathrm{s}}$ appears to depend directly on the type of surface compound resulting on the metal[2].

The dynamic feature of rough $\mathrm{Au}$ surfaces in contact with aqueous solutions as well as the marked influence of the electrolyte composition on the mobility of Au surface atoms questions the use of Au tips for in situ STM imaging of metal/electrolyte interfaces. The changes of the tip shape at atomic level appear at present difficult to control.

\section{CONCLUSIONS}

The electrochemical method reported earlier[4] to estimate surface diffusion coefficients of metals in aqueous solutions provides reliable data for $\mathrm{Au}$ electrodispersed electrodes in $0.5 \mathrm{M} \mathrm{H}_{2} \mathrm{SO}_{4}$. In this case, the surface diffusion coefficient of $\mathrm{Au}$ atoms changes by adding different substances. According to the type of additive, either a protection of the rough structure or the reverse effect can be produced. The first situation arises by adding $\mathrm{Py}$ to $0.5 \mathrm{M} \mathrm{H}_{2} \mathrm{SO}_{4}$, whereas the second one appears when small amounts of $\mathrm{Cl}^{-}$ions are present in the same solution. A preferred orientation of $\mathrm{Au}$ crystallites through $\mathrm{Au}$ surface reconstruction is coupled to the changes in particle size occurring during roughness decay. The present results offer a quantitative approach for studying the surface diffusion of Au atoms in electrochemical studies.

Acknowledgements-A fellowship from the Consejo Nacional de Investigationes Científicas y Técnicas (Argentina) to R.C.S. is gratefully acknowledged. This work was partially supported by the Organization of the American States through the Scientific and Technological Development Program.

\section{REFERENCES}

1. R. P. Messmer, in The Nature of Surface Chemical Bond (Edited by T. N. Rhodin and G. Ert1), North-Holland, Amsterdam (1979).

2. J. R. Galvele, J. electrochem. Soc. 133, 953 (1986); Corros. Sci. 27, 1 (1987).

3. G. Ehrlich and K. Slolt, Ann. Rev. phys. Chem. 31, 603 (1980).

4. C. Alonso, R. C. Salvarezza, J. M. Vara, A. J. Arvia, L. Vázquez, A. Bartolomé and A. M. Baró, J. electrochem. Soc., in press.

5. S. Trassati and D. A. Petrii, Real Surface Area Measurements in Electrochemistry, Commission on Electrochemistry, IUPAC, in press.

6. A. J. Arvia, R. C. Salvarezza and W. E. Triaca, Electrochim. Acta 34, 1057 (1989).

7. J. Gómez, L. Vázquez, A. M. Baró, C. Alonso, E. González, J. González-Velasco and A. J. Arvia, J. electroanal. Chem. 240, 77 (1988).

8. L. Vázquez, A. Bartolomé, A. M. Baró, C. Alonso, R. C. Salvarezza and A. J. Arvia, Surf. Sci. 215, 171 (1989).

9. B. K. Chakraverty, J. Phys. Chem. Solids 28, 2401 (1967).

10. A. Chialvo, W. E. Triaca and A. J. Arvia, J. electroanal. Chem. 171, 303 (1984).

11. M. E. Vela, R. C. Salvarezza and A. J. Arvia, Electrochim. Acta, in press.

12. A. Chialvo, W. E. Triaca and A. J. Arvia, J. electroanal. Chem. 146, 93 (1983).

13. A. Hamelin, J. electroanal. Chem. 144, 365 (1983); 255, 281 (1988).

14. L. Stolberg, J. Richer, J. Lipkowski and D. Irish, J. electroanal. Chem. 207, 213 (1986); L. Stolberg, J. Lipkowski and D. Irish, J. electroanal. Chem. 238, 333 (1987); D. Bode, T. Andersen and H. Eyring, J. phys. Chem. 71, 792 (1967).

15. D. Kolb, G. Lehmpfuhl and M. Zei, J. electroanal. Chem. 179, 298 (1984); A. Hamelin, J. electroanal. Chem. 210, 303 (1986).

16. H. Angerstein-Kozlowska, B. E. Conway, A. Hamelin and L. Stoicoviciu, J. electroanal. Chem. 228, 429 (1987).

17. R. C. Weast (Editor), Handbook of Chemistry and Physics, CRC Press, Florida (1979).

18. D. Dickermann, J. W. Schulzte and K. J. Vetter, J. electroanal. Chem. 59, 429 (1974).

19. H. P. Bonzel, in Surface Physics of Materials (Edited by J. M. Blakely), p. 280, Academic Press, New York (1975).

20. T. Lin and Y. Chung, Surf. Sci. 207, 539 (1989).

21. J. J. Bikerman, Physical Surfaces, Academic Press, New York (1970).

22. D. J. Rogers, S. D. Luck, D. Irish, D. Guzonas and G. Atkinson, J. electroanal. Chem. 167, 237 (1984).

23. J. K. Gimzewski, A. Humbert, J. G. Bednorz and B. Reihl, Phys. Rev. Lett. 55, 951 (1985); A. Humbert, J. K. Gimzewski and B. Reihl, Phys. Rev. B32, 4252 (1985); J. K. Gimzewski and A. Humbert, IBM J. Res. Dev. 30, 472 (1986).

24. F. Sette, T. Hashizume, F. Comin, A. A. MacDowell and P. H. Citrin, Phys. Rev. Lett. 61, 1384 (1988).

25. J. Wiechers, T. Twomey, D. Kolb and R. J. Bhem, J. electroanal. Chem. 248, 451 (1988).

26. D. J. Trevor, C. E. Chidsey and D. N. Loiacono, Phys. Rev. Lett. 62, 929 (1989).

27. K. Reichlt and H. O. Luzt, J. Crystal Growth 10, 103 (1971); C. E. D. Chidsey, D. N. Loiacono, T. Sleator and S. Nakahara, Surf. Sci. 200, 45 (1988). 